\title{
Discussion on Manufacturing and Services Integration Based on E-Commerce Platform
}

\author{
Jinfa $\mathrm{Li}^{1}$ and Guangcheng $\mathrm{Liu}^{1}$ \\ ${ }^{1}$ School of Management Engineering, Zhengzhou University, Zhengzhou 450001, China \\ Email: lijinfa@zzu.edu.cn,272572784@qq.com.
}

\begin{abstract}
The integration of manufacturing and services is the key to adapt to the inevitable requirement of the revolution of the development of a new round of mobile Internet industry. They are also the key and trend of the next period to enhance the quality and efficiency of Chinese's manufacturing industry to release potential services development fully, and cultivate new economic growth point.Meanwhile it makes it more effective than before.The enterprises can publicize their own values as well as collect and deal with consumer feedback of the product experience more effectively.And then,it can grasp the market trends and adapt to developping world more quickly.
\end{abstract}

Keywords. Manufacture, services, industry integration, mobile internet.

\section{Introduction}

With the rapid development of modern information technology, manufacturing and services integration have become the mainstream trend of modern industrial development, And it also the main driving force of promoting global industrial upgrading. The services and the manufacturing show a trend interactionsy and mbiotic interdependence.And then it constantly give birth to new industries and new format, so as to promote economic transformation from the industrial structure to services economy [1] plays an increasingly more important role. And the fierce competition in the E-economic platform made the competition of original price and quality of goods be the current competition of services [2].The services includes price, quality, and user experience and so on [3]. The academic papers and related institutions concerned more about the question of the integration of manufacturing and service industries national [4] or regional [5] as well as in the fusion path [6]. Now this paper will explore the process of how they interact with each other in the process of integration manufacturing and services.

\section{The Problems and Current Situation Before The Integration Of Manufacturing And Services}

\subsection{Manufacturers have low market-perceived capabilities}

Manufacturers need spend serval and even more experie-ncing product research, design, selection of materials be-fore production.In the era of morden market,information changes fast, consumer's demand is diverse and volatile. If the manufacturer's perceive abil- ity and foresight abi- lity are very strong, it may be able to adapt to market ch-anges, or it will be difficult to survive.

\subsection{Distributor are more sensitive to the market}

Distributor can know the evaluation of product featu- res, style in service and quality directly when consumption.Especially in the era of e-commerce, in the e-commerce platform, the customer care know the cu- stomers' satisfaction level of product's feature,style and material when they talk each other.Then distrib-utor can summarize the good's advantages and disa-dvantages.After market customer service will know about the feeling about the customer experience m-ore intuitively when they communicate with consum- ers. Therefore, the distributor will conclude the demand of the good basing on the information, then they find the target product.By this way, they can improve their own serivices constantly.In the ear of information today, it not only accelerates the spreed of information, but also accelerates the competition.It is more difficult for manufactu- rers to survive especially smaller.Only distributors must 


\subsection{Cooperating with each other is difficult}

Distributor and manufacturers 'focusing point is different. For the same to capture high profits, distributors focus the point of improving service levels. But manufacturers are more care about their own products and whether the concept of the design product is recognized or not by society. Distributors and manufacturers concerned about the different groups, The species of manufacturers' product is singal, so manufacturers focuse more about a single product and its corresponding group is single too, But the number of the group is larger. Distributors' product species is more than manufacturers'.so the target groups smaller, and its personality and characteristics are more obvious. In the ear of the information, the group of pursuiting fast fashion is restless, and the younger, the more serious.

Normally, the scale of distributors is small, so most distributors are unable to publicize his goods on the ecommerce platform On a large scale. In order to increase the number of customer, distributors will choose more types of products. But manufacturers don't have so many species especially for small enterprises. In order to allow people to accept their products, manufacturers must publicize their own product ideas so that it spreads in the crowd of target group. Therefore, when the product can't meet the needs of the market in time, the manufacturer cannot get the consumers' feedback of product form distributor, the distributor cannot yet get support from the manufacturer about product optimization.so they cannot cooperate with each other too.

\section{The positive meaning of industrial integration}

\subsection{Improve the control ability and the service level in terms of consumption}

Information transmission between enterprises and consumers is the most direct and rapid through e-commerce platform. Perceptions of consumer truly reflects the consumer experience, the direct dialogue improve the directness and effectives of information transmission. According to the consumer experience, enterprises can optimize the product in order to make every customer satisfied. Accurate positioning of the market, fully display the brand culture, spread the value of enterprises.

\subsection{Reduce inventory costs and operational risk}

Inventory risk is the problem of traditional enterprise is inevitable. From the early Lining to XTEP and PEAK, they were all malaise for years or even bankrupty because of inventory problem. While e-commerce enterprises can base on the platform of large data monitoring product popularity and purchase quantity and more accurately predict product sales quantity. But traditional business is difficult to achieve it. The first brand of clothing electronic commerce Inman, sold over one million pieces of clothing with the inventory less than $10 \%$ at end of the year which below the average inventory level of $70 \%$ inventory of traditional women brand.

\section{The diagram of services and manufactures integration model}

\subsection{Industrial convergence model diagram}

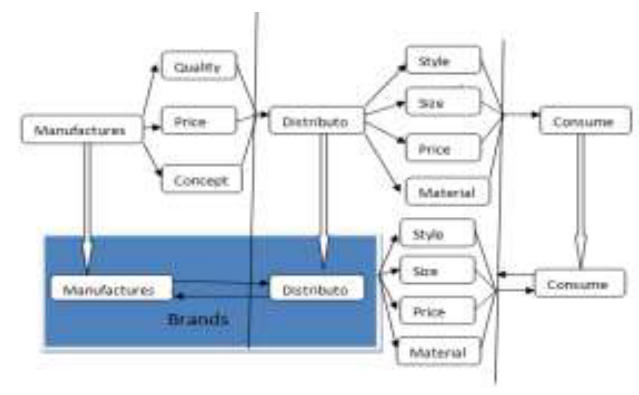

Fig. 1. Industrial convergence model diagram.

Manufacturers and service providers, consumer was the state of the upstream and downstream before the integration of industries. The information from the consumer to the service provider and then to the manufacturer should go through two stages, the transmission effect decreasing step by step. After the industry convergence, manufacturers and service merge into one, and its ternary interaction before fusion become binary interaction. From two levels of information transmission to one level and greatly increase the transmission speed of information. The change between manufacturer 
and service provider of information transfer is: from the external transfer into internal transfer; from passive transfer into active transfer, this improves the transmission speed and efficiency. Consumer's information feedback is adopted, and it improves the interactive enthusiasm of consumers. The manufacturer and service provider improve their company's performance due to the utilization of information. After the integration of the industry, manufacturers and service providers are not only simple sale goods, but more delivery the value of the brand from selling goods to do the brand, from short-term shop to long-term brand building.

\subsection{Industry convergence case: Inman [7]}

\subsubsection{Business background}

2005, Fang Jianhua joined Alibaba integrity, the initial contact with electronic commerce. 2007 registered Inman brand, began to test the domestic market. 2007 began to develop the mobile Internet, Fang Jianhua divides the company's business, Inman officially settled in Taobao, turnover of several million, profit for the loss. The same year to stay Taobao Mall (the predecessor of the Tmall). 2009, 2010, Inman loss of the previous year to reach more than two million in the electricity business. 2010 Inman for the first time to participate in the double eleven, the day sales record of 6.8 million, annual trading volume of 70 million, the basic line of profit and line flat. 2011, with 17.87 million sales ranked Tmall women's wear brand. The annual turnover of 140 million. 2012, with a single day sales of 70 million refresh brand history, order trading volume of 330 thousand. 2012, annual turnover of more than 300 million. 2013, Inman day sales exceeded 120 million, becoming the first full-line sales of women's brand. 2013 annual turnover exceeded 590 million. 960 million in 2014. 2015 annual turnover is more than 1.1 billion mark.

\subsubsection{Industrial integration performance}

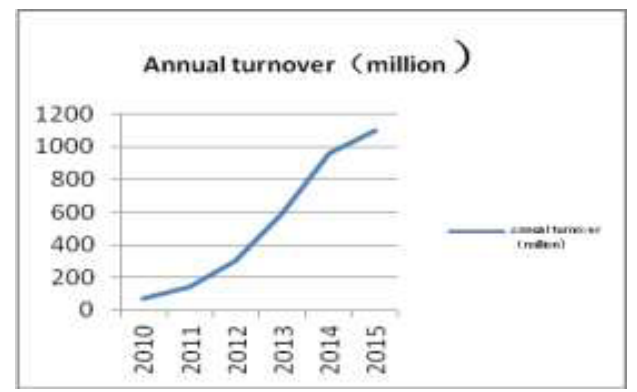

Fig. 2. Inman calendar year turnover after the integration of industry

\section{Conclusion}

Consumers continue to highlight the personality, small and beautiful things continue to be sought after. Mass pro duction of traditional enterprises is becoming increasing ly difficult to adapt the fast fashion consumer environment.

The development of the whole industry chain has become a new profit growth mode, with the manufacturing and service integration continues to increase, New technologies, new formats, new management models are emerging, to promote more refined industrial division of labor, the value chain of the industry value chain has become more and more, Products from the development, production to marketing, distribution, maintenance, and so on, the formation of the value chain process began to decompose, integration and reconstruction, Products in the manufacturing process only a small part of the time, most of the time in R \& D, procurement, storage, operation, sales, aftersales service, etc, The industry chain more c-oncentrated in producer service sectors, the efficiency, valueadded space, profit margins of these services on the whole industry chain are great influence, thus becoming the industry-wide value-added, the main source of profit, but also the whole industry control decision facto- rs. With ecommerce from the sales side to the designside penetration, reduce production costs, optimize product features will be the main function of e-commerce.

Enhance interaction with consumers, the development of fan economy. Fans of the economy are now a new marketing model, the company through the use of brand promotion, to win fans to achieve economic efficiency. Fans of the economy from the identification of the prod-uct, is the product of the concept of affirmation, fans of the economy continues to improve the quality of the product, but also the continuous improvement of user experience. This need to continue to increase the depth of industrial integration.

\section{References}

1. Wang Xiaohong. Six Trends Of The Convergence Of Manufacturing And Service.New Chongqing.2014.08 
2. Xing Xiangjun.Study On The Influencing Factors Of E-commerce Service Industry In China. Commercial Times.2014.07

3. Lin Nan To Promote Industrial Upgrading By The Integration Of Services And Manufacturing Industry. Macroscopic economy.2010.08.

4. Li Jianzhong Grasp the trend of sthe integration of manufacturing industry and services .Zhengjiang Economy.2015.

5. Li Bo An Study on Interactive of Producer Services and Manufacturing Industry: A Case Study of Dalian 2011.05

6. The Integration of Manufacturing and Service Based on Independent Innovation: Mechanism and Path. Journal of Nanjing University.2012.

7. The Interview Of Wang Jiangzhong.2013.09 